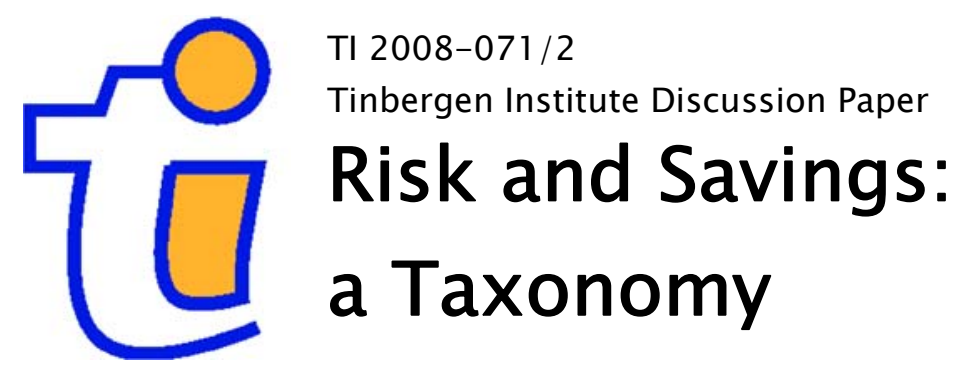

Jan Willem Gunning

VU University Amsterdam, and Tinbergen Institute. 


\section{Tinbergen Institute}

The Tinbergen Institute is the institute for economic research of the Erasmus Universiteit Rotterdam, Universiteit van Amsterdam, and Vrije Universiteit Amsterdam.

Tinbergen Institute Amsterdam

Roetersstraat 31

1018 WB Amsterdam

The Netherlands

Tel.: +31(0)205513500

Fax: $+31(0) 205513555$

Tinbergen Institute Rotterdam

Burg. Oudlaan 50

3062 PA Rotterdam

The Netherlands

Tel.: + $31(0) 104088900$

Fax: $+31(0) 104089031$

Most TI discussion papers can be downloaded at http://www.tinbergen.nl. 


\title{
Risk and Savings: a Taxonomy
}

\author{
Jan Willem Gunning
}

VU University Amsterdam and Tinbergen Institute

JEL Codes: D11, D91, O12, O16

Corresponding author:

Jan Willem Gunning

Dept. of Economics (FEWEB), 2E69

VU University Amsterdam

De Boelelaan 1105

$1081 \mathrm{HV}$ Amsterdam

The Netherlands

tel. $+31-20-5986141$

fax +31-20-5986004

e-mail jgunning@feweb.vu.nl 


\begin{abstract}
Risk may induce precautionary saving but it can also reduce saving. The theoretical literature recognizes both possibilities, but favors a positive effect (both for developed and developing countries); the empirical literature is divided, reporting (small) positive effects for developed economies and (large) negative effects for developing countries. We show in a 2-period model how the effect of risk on savings depends not only on preferences but also on the type of risk.
\end{abstract}




\section{Introduction}

Does risk induce agents to save more or is the effect negative so that risk reduces growth? The theoretical literature recognizes both possibilities but favors a positive effect, both for developed countries (Browning and Lusardi, 1996) and for developing countries (Deaton 1991, Besley, 1995). The empirical literature is divided: studies of developed economies typically find a small positive effect (Browning and Lusardi, 1996; Lusardi, 1998) while recent studies for developing countries find large negative effects (Dercon, 2005). This confusing state of affairs is easily explained: the literature focuses on how preferences affect the impact of risk on savings, but has paid little attention to how the effect depends on the type of risk. ${ }^{1}$

This is the subject of this Note. The objective is to classify the combinations of preferences, type of risk and income processes which in a standard 2-period model will give rise to a positive, negative or zero impact of risk on savings. The key point is that the effect may well be negative if the asset used for saving is itself subject to risk or if the returns to saving are risky. These circumstances are common in developing countries.

The effect of risk on savings has usually been studied under the assumptions that agents maximize expected utility, that they have intertemporally additive and non-quadratic utility functions with a constant discount factor, that expectations are rational and that there is a perfect capital market. ${ }^{2}$ Typically, only labor income is risky. It is well known (Leland, 1968) that under these assumptions the effect of risk on savings is positive if the utility function exhibits prudence $\left(u^{\prime \prime \prime}>0\right)$. Since most authors assume constant relative risk aversion (which implies prudence) a positive effect of risk on savings is a standard result in this literature. ${ }^{3}$

It has often been suggested that in developing countries exposure to large uninsured risks reduces the savings rate and thereby economic growth. This cannot be reconciled with the usual assumptions of constant relative risk aversion and labor income risk. However, it is consistent with risk affecting assets or the return to assets. ${ }^{4}$

\footnotetext{
${ }^{1}$ For example, Dasgupta (1993, pp. 262-3) claims that the conclusion of Deaton (1990) that CRRA is sufficient for a precautionary motive is incorrect. However, Deaton assumes income risk (so that CRRA is sufficient), Dasgupta wealth risk.

2 These assumptions define the standard additive model (Browning and Lusardi, 1996, p. 1802). A quadratic utility function rules out prudence (Kimball, 1990).

${ }^{3}$ This is a relatively recent phenomenon. For example, Hahn (1970) assumed wealth risk. The standard additive model has been generalized in various ways but the assumption that risk affects only labor income is typically maintained, e.g. Weil (1993).

${ }^{4}$ Dercon (1995, appendix) shows that if assets are risky consumption smoothing is much less effective than in the model of Deaton $(1990,1991)$. Dercon used simulation experiments to investigate the impact of various types of risk on welfare. Here we focus on the impact on savings.
} 
We show that the effect is negative if households are moderately risk averse and if asset or capital income risk dominates labor income risk. This case seems plausible. For example, in much of Africa the key asset is livestock (which is subject to numerous risks, including drought and disease risk) and in many rural societies a large part of household income is derived from farming where livestock is used as a productive asset. ${ }^{5}$ With this conjunction an increase in uninsured risk is indeed likely to reduce savings.

\section{Risk and Saving in a Two-Period Model}

Consider a 2-period model with a single asset, time-additive utility, fixed terms of trade and constant relative risk aversion (CRRA). ${ }^{6}$ The agent maximizes expected utility:

$$
\max _{k \geq 0} u\left(c_{1}\right)+\beta E u\left(c_{2}\right)
$$

subject to

(1) $c_{1}=w-k$

and $\quad(2) \quad c_{2}=f(s, y, k)$

where $k$ denotes savings, $w$ wealth on hand in period $1, \beta$ the discount factor $(0<\beta<1), u$ the utility function and $c_{t}$ consumption $(t=1,2)$. The CRRA assumption implies that marginal utility is given by $u^{\prime}(c)=c^{-R}$ where the degree of relative risk aversion $R$ is a positive constant. We will assume an interior solution $(k>0){ }^{7}$ Period 2 wealth on hand, $f(s, y, k)$, is a function of a shock $s$, expected labor income $y$ and $k$. The agent knows the distribution of $s$.

The first-order condition is

$$
\text { (3) } u^{\prime}\left(c_{1}\right)=\beta E u^{\prime}\left(c_{2}\right) \frac{\partial c_{2}}{\partial k} \text {. }
$$

As is well known, this Euler condition can be used to investigate the effect of risk on savings. Define

$$
\varphi(s)=u^{\prime}\left(c_{2}\right) \frac{\partial c_{2}}{\partial k} .
$$

\footnotetext{
${ }^{5}$ Labor income risk is quite small (relative to asset risk) in the rural societies of Zimbabwe (Elbers et al., 2007) and Ethiopia (Pan, 2008). Both studies use panel data to estimate a stochastic growth model. They both find evidence of log utility $(R=1)$ and a massive negative effect of risk on savings.

${ }^{6}$ Dercon (2005) analyzes changes in the terms of trade (the relative price of the asset in terms of the consumption good).

${ }^{7}$ In a 2-period model the other possibility is of little interest: if the borrowing constraint is binding $c_{1}=w$ and small changes in risk do not affect the solution. In a multi-period model the possibility that liquidity constraints will bind at some future time can affect the decision taken today (e.g. Deaton, 1991, Carroll and Kimball, 2001).
} 
If this function is strictly convex in $s$ then an increase in risk (a mean preserving spread in the distribution of $s$ ) will increase the right hand side of (3). This requires a compensating increase in savings, $k$. Therefore, if $\varphi(s)$ is strictly convex (concave) the effect of an increase in risk on savings is positive (negative).

Wealth at the end of period 2 is given by

(4) $f(s, y, k)=s_{1} y+s_{2}(1-\delta) k+s_{3} \mu(k)$

where $y$ is expected labor income (which is exogenous and non-negative), $(1-\delta) k$ the expected value of assets, and $\mu(k)$ the expected value of capital income. The depreciation rate satisfies $0<\delta<1$ and the function $\mu(k)$ is increasing and concave, with $\mu(0)=0.8$ Each of the three terms can be affected by a multiplicative shock $\left(s_{i}>0, E s_{i}=1, i=1,2,3\right)$.

We consider four special cases: labor income risk $\left(s=s_{1}\right)$, wealth risk $\left(s=s_{1}=s_{2}=s_{3}\right)$, asset risk $\left(s=s_{\Downarrow} 2\right)$, and capital income risk $\left(s=s_{\mathrm{a}}\right)$.

\section{I labor income risk $c_{2}=s y+(1-\delta) k+\mu(k)$}

This case, first analyzed by Leland (1968), is now the most common one in the theory of savings. ${ }^{9}$ The function $\varphi(s)=\left[(1-\delta)+\mu^{\prime}(k)\right] /[s y+(1-\delta) k+\mu(k)]^{R}$ is strictly convex in $s$. Therefore the effect of risk on savings is positive, irrespective of the value of $R$.

\section{II wealth risk $c_{2}=s[y+(1-\delta) k+\mu(k)]=s \lambda(y, k)$}

In this case, first analyzed by Hahn (1970), risk affects all wealth in the same way. Denote the partial derivative of $\lambda(y, k)$ with respect to $k$ by $\lambda_{k}$. Then

$$
\varphi(s)=u^{\prime}\left(c_{2}\right) s \lambda_{k}=\frac{s \lambda_{k}}{[s \lambda]^{R}}=\frac{\lambda_{k}}{\lambda^{R}} s^{1-R} .
$$

Hence $\varphi(s)$ is strictly convex (concave) in $s$ if the degree of relative risk aversion is greater (less) than 1 . It follows immediately that the effect of risk on savings is positive for $R>1,0$ for $R=1$ and negative for $R<1$.

III asset risk $c_{2}=y+s(1-\delta) k+\mu(k)$

\footnotetext{
${ }^{8}$ This specification covers two important special cases. If the agent has access to a perfect capital market with given interest rate $r$ then $\underline{k}(k)=r k$. Conversely, a farm household in a developing country may only be able save in the form of on-farm investment; $\mu(k)$ would then be strictly concave.

${ }^{9}$ For an excellent discussion of labor income risk in a multi-period model see Deaton (1992, pp. 26-29). Deaton there assumes a constant interest rate, i.e. $k k^{\prime} k=r k$.
} 
In this case

$$
\varphi(s)=\frac{s(1-\delta)+\mu^{\prime}}{[y+s(1-\delta) k+\mu]^{R}}
$$

hence

$$
\varphi^{\prime}(s)=(1-\delta) \frac{y+s(1-\delta) k(1-R)+\left(\mu-R \mu^{\prime} k\right)}{[y+s(1-\delta) k+\mu]^{R+1}}
$$

and

$$
\varphi^{\prime \prime}(s)=(1-\delta)^{2} k R \frac{-2 y+s(1-\delta) k(R-1)-\left(\mu-\mu^{\prime} k\right)-\left(\mu-R \mu^{\prime} k\right)}{[y+s(1-\delta) k+\mu]^{R+2}} .
$$

The sign of this derivative depends not only on the value of $R$ but also on whether exogenous income $y$ is positive and on whether or not $\mu(k)$ is strictly concave. If $\mu$ is linear then the third term drops out and both the second and the fourth term have the sign of $R-1$ (while, obviously, the first term has the sign of $\mathbf{l} y$ ). Conversely, if $\beta(k)$ is strictly concave then the third term is negative and so is the fourth term, except when $R \geq \mathbf{1}$ in which case the sign of that term is ambiguous. It follows that the sign of the effect of risk on savings is as shown in Table 1.

\section{Table 1: Effect of Asset Risk on Savings}

$\begin{array}{cccc} & \mu(k) \text { linear } & \mu(k) \text { linear } & \mu(k) \text { strictly concave } \\ & y=0 & y>0 & y \geq 0 \\ \mathrm{R}<1 & - & - & - \\ \mathrm{R}=1 & 0 & - & - \\ \mathrm{R}>1 & + & ? & ?\end{array}$

IV capital income risk $c_{2}=y+(1-\delta) k+s \mu(k)$

In this case

$$
\varphi(s)=\frac{(1-\delta)+s k^{k}}{\left[y+(1-\delta)_{k}+s\right]^{k}}
$$

It follows (after some tedious algebra) that

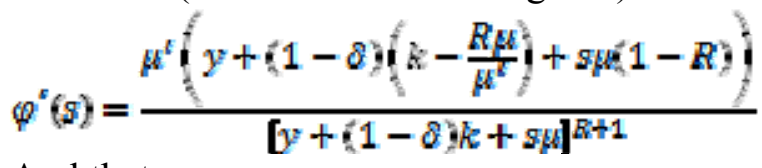

And that 


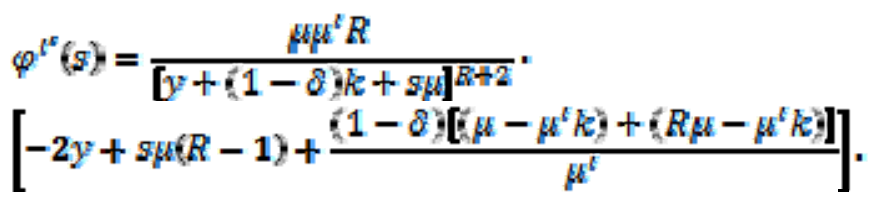

We can sign the four terms as before; the results are shown in Table 2.

Table 2: Effect of Capital Income Risk on Savings

\begin{tabular}{ccccc} 
& \multicolumn{2}{c}{$\mu(k)$} & linear & \multicolumn{2}{c}{$\mu(k)$} & strictly concave \\
& $y=0$ & $y>0$ & $y=0$ & $y>0$ \\
$\mathrm{R}<1$ & - & - & - & $?$ \\
$\mathrm{R}=1$ & 0 & - & - & $?$ \\
$\mathrm{R}>1$ & + & $?$ & $?$ & $?$
\end{tabular}

We summarize the results for the four types of risk in Table 3.

Table 3: Types of Risk and the Effect of Risk on Savings

$\begin{array}{ccccc} & \mu(k) \text { linear } & \mu(k) & \text { strictly concave } \\ \text { labor income } & \text { wealth } & \text { asset or capital income } & \text { asset } & \text { capital income } \\ y=0 \quad y>0 & y \geq 0 & y=0 \quad y>0\end{array}$

$\begin{array}{llllllll}R<1 & + & - & - & - & - & ? & ? \\ R=1 & + & 0 & 0 & - & - & + & ? \\ R>1 & + & + & + & ? & ? & + & ?\end{array}$

Clearly, the effect of risk on savings depends on the type of risk. For example, for log utility $(R=1)$ the savings effect is positive for labor income risk, 0 for wealth risk and negative for asset risk (provided $\mu$ is strictly concave). The suggestion in the literature that $R>1$ is sufficient for a positive effect ${ }^{10}$ is clearly unwarranted. Note that it is important to distinguish between capital income risk and asset risk: the effect on saving can be of opposite sign. In reality agents often face more than one form of risk. Whether an increase in risk reduces or increases savings may then depend on which type of risk dominates. ${ }^{11}$

Note that for moderate risk aversion $(R \leq 1)$ and positive labor income the effect of asset risk on savings is negative (and the effect of capital income risk can be negative). This suggests that savings will be overestimated by models which allow only for labor income risk when in fact households do not have access to a safe asset. This might help explain why savings in developed countries appear to be "too low" (Browning and Lusardi, 1996):

\footnotetext{
${ }^{10}$ E.g. Dasgupta (1993), p. 263.

${ }^{11}$ Elbers et al. (2007) and Pan (2008).
} 
in these countries saving is largely for retirement and a substantial part of such savings is invested in the stock market.

\section{Conclusion}

There is a presumption in the literature on developed countries that the effect of risk on savings is positive (and possibly small). Conversely, for developing countries recent evidence suggests that risk can have a large negative effect on savings and growth. We have used a 2-period model to analyze under what circumstances this is the case. 


\section{References}

Besley, T., 1995, Savings, Credit and Insurance, in: J. Behrman and T.N. Srinivasan (eds.), Handbook of Development Economics, Vol. 3A (North-Holland: Amsterdam) 2123-2207.

Browning, M. and A. Lusardi, 1996, Household Saving: Micro Theories and Micro Facts, Journal of Economic Literature 34, 1797-1855.

Carroll, C.D. and M.S. Kimball, 2001, Liquidity Constraints and Precautionary Savings, NBER Working Paper W8496.

Dasgupta, P., 1993, An Inquiry into Well-Being and Destitution. (Clarendon Press, Oxford).

Deaton, A., 1990, Saving in Developing Countries: Theory and Evidence, Proceedings of the World Bank Annual Conference on Development Economics 1989, supplement to the World Bank Economic Review, 61-96.

Deaton, A., 1991, Saving and Liquidity Constraints, Econometrica 59, 1221-1248.

Deaton, A.,1992, Understanding Consumption. (Clarendon Press, Oxford).

Dercon, S., 2005, Risk, Insurance and Poverty: a Review, in: S. Dercon (ed.), Insurance against Poverty, (Oxford University Press: Oxford) 9-37.

Elbers, C., J.W. Gunning and B. Kinsey, 2007, Growth and Risk: Methodology and Micro

Evidence, World Bank Economic Review 21, 1-20.

Hahn, F., 1970, Savings and Uncertainty, Review of Economic Studies 37, 21-24.

Kimball, M.S., 1990, Precautionary Saving in the Small and in the Large, Econometrica 58, 5373.

Leland, H.E., 1968, Saving and Uncertainty: the Precautionary Demand for Saving, Quarterly Journal of Economics 82, 465-473.

Lusardi, A., 1998, On the Importance of the Precautionary Saving Motive, American Economic Review, Papers and Proceedings 88, 449-453.

Pan, L., 2008, Poverty, Risk and Insurance: Evidence from Ethiopia and Yemen, unpublished $\mathrm{PhD}$ thesis, VU University Amsterdam.

Weil, P., 1993, Precautionary Savings and the Permanent Income Hypothesis, Review of Economic Studies 60, 367-383. 